\title{
APS-TD Cleanroom Facilities
}

\author{
D. Bice C. Baker, B. Kuhn, A. Penhollow
}

FERMILAB-POSTER-20-008-TD

\section{Cleanrooms}

4 cleanrooms within the control of APS-TD, all with their own class 1000, Class 100, and Class 10 areas.

Each cleanroom equipped with areas suited for parts cleaning and preparation, particle free assemblies, UHV evacuation, leak detection and residual gas analysis.
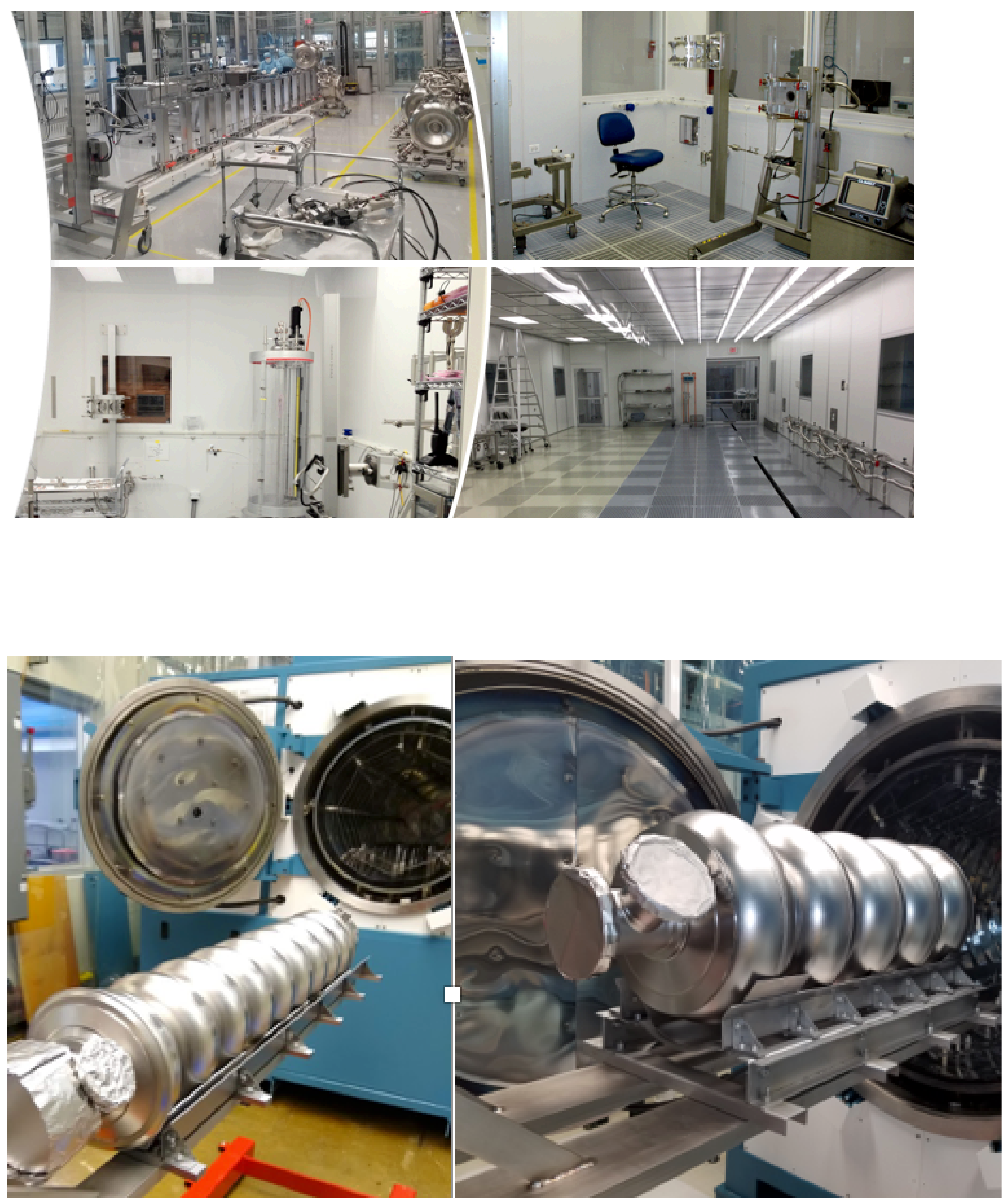

\section{High Temperature Vacuum Furnaces}

Currently 2 UHV furnaces are in use, with a $3^{\text {rd }}$ being recommissioned for smaller component and sample studies.

The largest furnace can accommodate a $650 \mathrm{MHz} 5$-cell cavity, while the smallest can accommodate higher frequency single cell cavities.

Bakes are done in vacuum, capable of max operating temperatures between $1100 \mathrm{c}$ and $1300 \mathrm{c}$.

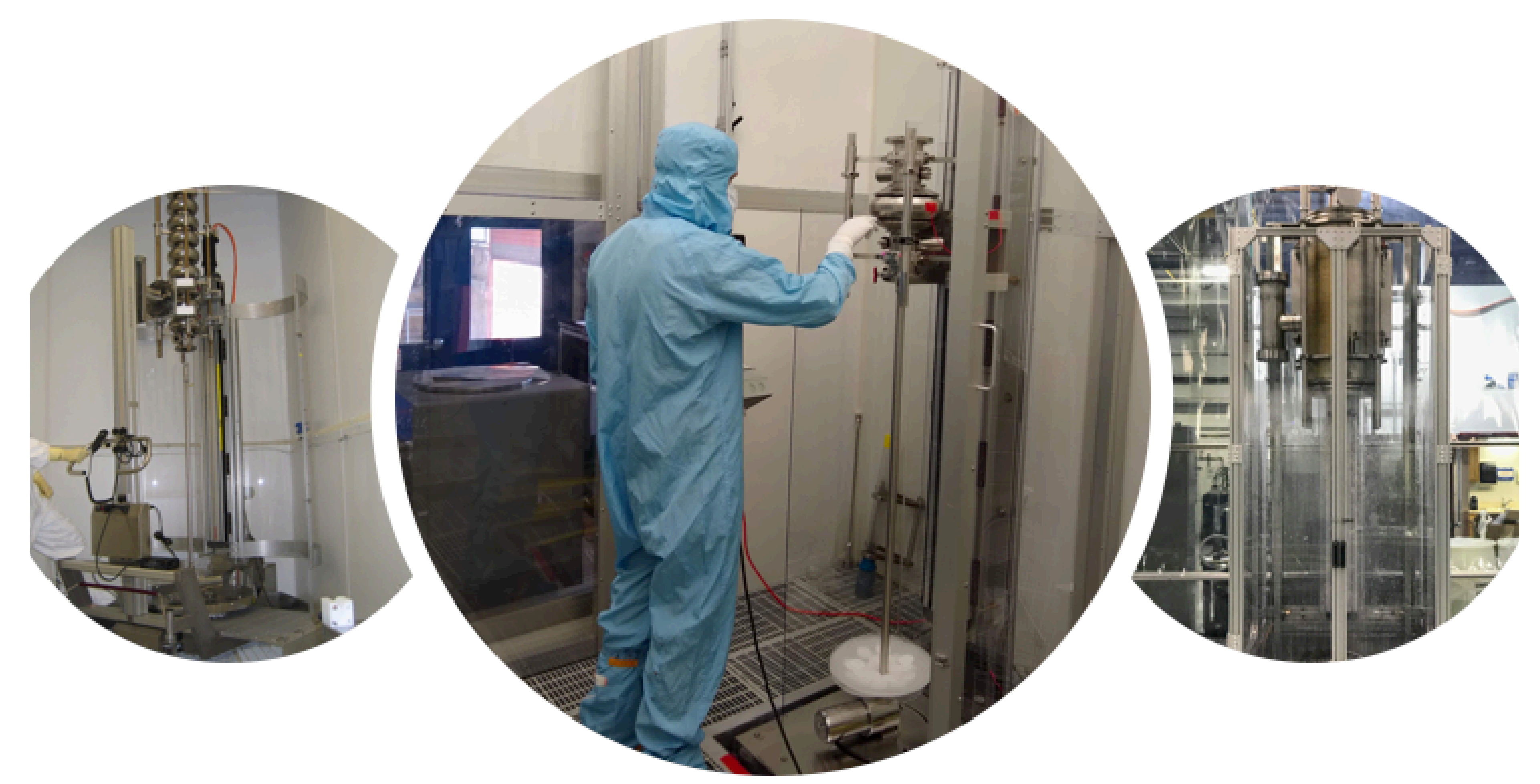

\section{High Pressure Rinsing}

3 cleanrooms equipped with high pressure rinsing units, including 3 vertical and 1 horizontal. Rinsing can be done at pressures up to 1300 p.s.i., adjustable down to $<400$ p.s.i.

Fan jet spray nozzles rotate on each, while vertical translation is provided by a Bosch type rail. Translation speeds are fully adjustable.

Water is made via $>18 \mathrm{M} \Omega \mathrm{DI}$ water plant.

\section{Multiple Extraneous Capabilities}
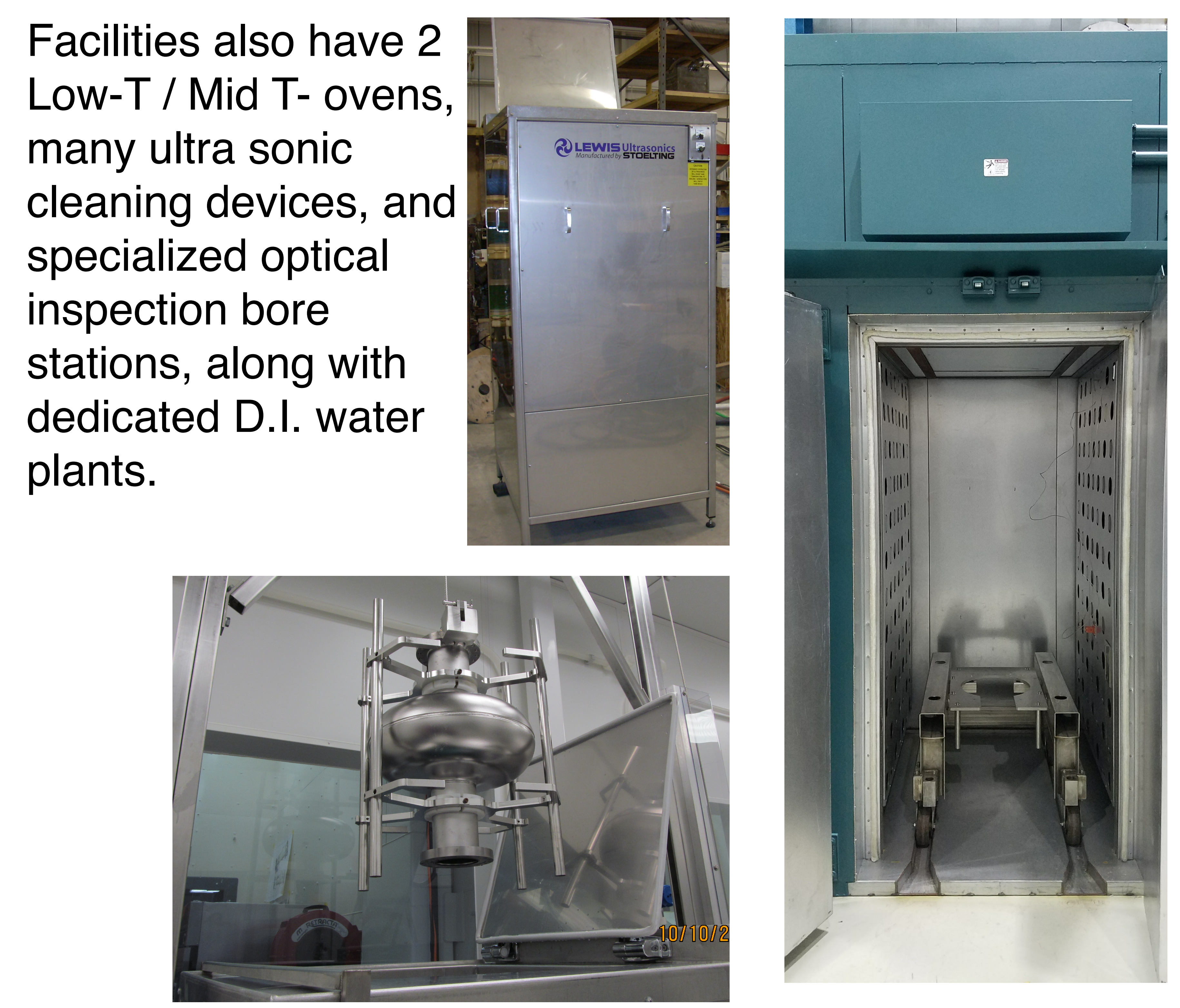

This manuscript has been authored by Fermi Research Alliance, LLC under Contract No. DE-AC02-07CH11359 with the U.S. Department of Energy, Office of Science, Office of High Energy Physics. 